\title{
Composição centesimal e de ácidos graxos do músculo Longíssimus de cordeiros confinados, alimentados com dietas contendo casca de mandioca
}

\author{
[Centesimal and fatty acid composition of the longissimus muscle of confined \\ lambs fed diets containing cassava peels] \\ G.S. Guimarães ${ }^{1}$, F.F. Silva ${ }^{2}$, L.L. Silva ${ }^{1}$, R.R. Silva ${ }^{2}$, J.I. Simionato ${ }^{2}$, J.M.A. Damásio ${ }^{2}$ \\ ${ }^{1}$ Aluno de pós-graduação - Universidade Estadual do Sudoeste da Bahia - UESB - Itapetinga, BA \\ ${ }^{2}$ Universidade Estadual do Sudoeste da Bahia - UESB - Itapetinga, BA
}

\begin{abstract}
RESUMO
Objetivou-se avaliar os efeitos de inclusão da casca da mandioca (CM) sobre a composição centesimal e de ácidos graxos do músculo Longíssimus de cordeiros. Foram utilizados 32 cordeiros mestiços Santa Inês, machos não castrados, peso corporal médio de $21 \pm 1,5 \mathrm{~kg}$. Os tratamentos foram distribuídos em delineamento inteiramente ao acaso aos animais, cujo os níveis de inclusão da $\mathrm{CM}$ foram $(0,10,20,30 \%)$ baseado na matéria seca da dieta. Utilizou-se como volumoso o feno da parte aérea de mandioca, e a relação volumoso:concentrado foi de 48:52. O experimento teve duração de 70 dias. Logo após, os cordeiros passaram por um jejum sólido de $16 \mathrm{~h}$ e, depois, foram abatidos. A carcaça foi conduzida à câmara fria, permanecendo por $24 \mathrm{~h}$, a uma temperatura de $4^{\circ} \mathrm{C}$. Na carcaça fria, foi retirada uma amostra do músculo Longíssimus, a qual foi congelada $\left(4^{\circ} \mathrm{C}\right)$, até o início das análises. Os resultados de umidade, cinzas e proteína não foram influenciados pela $\mathrm{CM}$, observando-se efeito linear decrescente para os teores de lipídeos. Com relação à composição de ácidos graxos, houve efeito linear para o C15:0 e efeito quadrático para C14:0, C18:0 e C22:0. Nos monoinsaturados, observou-se efeito linear para C16:1, C18:1-9c e C22:1-9c e efeito quadrático para C15:1, C17:1 e C20:1; já nos poli-insaturados, foi observado efeito linear para CLA, C20:3n-6, C20:4n-6, C20:5n-3 e C22:6n-3, e quadrático para C20:2 e C18:3n-6. Assim, conclui-se que a composição centesimal e de ácidos graxos apresenta variações em razão da inclusão da $\mathrm{CM}$, porém não compromete a qualidade da carne.
\end{abstract}

Palavras-chave: alimento alternativo, carcaça, qualidade da carne

\begin{abstract}
This study sought to evaluate the effects of the inclusion of cassava peel on the centesimal composition and fatty acids of the Longissimus muscle of lambs. We used 32 uncastrated crossbred Santa Inês lambs, with average body weight of $21 \pm 1.5 \mathrm{~kg}$. Treatments were in a completely randomized design, with the inclusion of cassava peel $(0,10,20,30 \%)$ in the diet dry matter. Hay from the cassava shoot has been used as forage and the forage:concentrate ratio was 48:52. The experiment lasted 70 days and then the lambs underwent a fast for 16 hours, were slaughtered, and their carcasses remained at a temperature of $4^{\circ} \mathrm{C}$ for 24 hours. In cold carcass the Longissimus muscle were taken and frozen $\left(4^{\circ} \mathrm{C}\right)$ until the analysis. The results for moisture, ashes and protein were not influenced by cassava peel, and a decreasing linear effect was observed for the lipids levels. In composition of unsaturated fatty acids, there was a linear effect for C15:0 and a quadratic effect for C14:0, C18:0 and C22:0. Regarding the monounsaturated fatty acids, a linear effect has been observed for C16:1, C18:1-9c and C22:1-9c, and a quadratic effect for C15:1, C17:1 and C20:1. With the polyunsaturated fatty acids, a linear effect was observed for CLA, C20:3n-6, C20:4n-6, C20:5n-3 and C22:6n-3, and a quadratic effect was seen for C20:2 and C18:3n-6. Thus, it is concluded that the centesimal and fatty acid composition varies depending on the inclusion of cassava peel, however, it does not compromise the quality of the meat.
\end{abstract}

Keywords: alternative feed, carcass, meat quality

Recebido em 5 de fevereiro de 2015

Aceito em 18 de fevereiro de 2016

E-mail: gguimaraes114@hotmail.com. 


\section{INTRODUÇÃO}

A ovinocultura é uma boa opção de produção para pequenos, médios e grandes produtores, determinada pelo incremento da demanda nos últimos anos. As raças ovinas especializadas para corte demonstram bom acabamento de carcaça e crescimento rápido, porém requerem manejo nutricional e sanitário mais rigoroso. Já os ovinos nativos, embora apresentem características qualitativas da carcaça aquém das exigências do mercado consumidor, apresentam adaptabilidade às condições do semiárido, predominantes no Nordeste. Entre as raças, pode ser citada a raça Santa Inês e mestiços (Araújo Filho et al., 2010).

Contudo, esses animais geralmente apresentam peso corporal desuniforme e idade avançada ao abate. Assim, os setores envolvidos na cadeia da carne ovina têm se mobilizado, no sentido de produzir animais precoces que imprimam qualidade ao produto. Porém, a ovinocultura, em sistemas intensivos, encontra obstáculos em relação à alimentação, um dos aspectos mais importantes na produção de carne.

Logo, alternativas alimentares surgem como uma forma de tentar promover a redução do uso de alimentos concentrados convencionais (Castro Filho et al., 2007).

Uma alternativa é a mandioca (Manihot esculenta Crantz), uma planta perene, arbustiva, pertencente à família das Euphorbiaceae (Nunes Irmão et al., 2008). A utilização de fontes alimentares alternativas, como a casca de mandioca, oriunda da indústria do beneficiamento da produção de farinha de mandioca, representa uma alternativa economicamente viável, uma vez que a mandioca é um alimento rico em amido, pobre em proteína bruta e mais barata que o milho (Holzer et al., 1997).

Contudo, nos últimos anos, as características de carcaça e de carne, especialmente a ovina, têm despertado atenção da comunidade científica e do mercado consumidor, tanto em relação aos aspectos quantitativos quanto aos qualitativos. A qualidade da carne é avaliada por parâmetros estruturais, físico-químicos e sensoriais, bem como por seu valor nutricional, sendo um fator importante o teor de gordura da carne e sua composição em ácidos graxos. Isso porque se tem discutido muito a relação nutrição humana e saúde, frente aos problemas relacionados à ingestão de determinados alimentos (McAFee et al., 2010).

Para que a ovinocultura brasileira possa concretizar a participação no mercado, maior atenção deve ser dada à qualidade da carne. Por essa razão, a indústria da carne busca alternativas para diminuir o teor de ácidos graxos saturados e aumentar o de ácidos graxos poli-insaturados, os ácidos graxos linoleico e linolênico, que são considerados essenciais, e também o ácido linoleico conjugado (CLA). Isso porque uma importante função da produção animal é fornecer carne de boa qualidade para a alimentação humana.

Assim, objetivou-se avaliar os efeitos dos níveis de inclusão da casca da mandioca na dieta de cordeiros confinados sobre composição centesimal e de ácidos graxos no músculo Longíssimus.

\section{MATERIAL E MÉTODOS}

O experimento foi desenvolvido na Casa Familiar Rural (CFR), localizada na Fazenda Novo Horizonte, no município de Presidente Tancredo Neves, estado da Bahia. Foi conduzido de acordo com as normas éticas e aprovado pela Comissão de Ética no Uso de Animais da UESB/Itapetinga (número do protocolo 76/2014).

Foram utilizados 32 cordeiros mestiços Santa Inês, machos não castrados, com idade aproximada de seis meses e peso corporal médio inicial de $21 \pm 1,5 \mathrm{~kg}$, identificados com brincos e vermifugados. Os animais permaneceram confinados em baias individuais de $12 \mathrm{~m}^{2}$, com piso de cimento, providas de bebedouros e comedouros. Os animais foram distribuídos em delineamento inteiramente ao acaso, com oito repetições por tratamento. Os tratamentos foram os níveis de inclusão da casca de mandioca $(0$, $10,20,30 \%$ ) em relação à matéria seca da dieta. Utilizou-se como volumoso feno da parte aérea de mandioca, e o concentrado foi formulado à base de milho, farelo de soja, casca de mandioca e mistura mineral. A proporção volumoso:concentrado foi de 48:52, respectivamente. 
As dietas foram calculadas para atender às exigências nutricionais de mantença de animais e ganho de 0,2kg/dia. (Tab. 1).

O feno da parte aérea da mandioca foi obtido pela Coopatan (Cooperativa de Produtores Rurais de Presidente Tancredo Neves), que utilizou talos e folhas da mandioca, fazendo a secagem industrial. A parte aérea da mandioca foi picada e conduzia ao secador industrial. Já a casca da mandioca, antes de ser utilizada, foi levada a um forno para secagem.

As dietas foram formuladas na tentativa de serem isonitrogenadas com $15 \%$ de $\mathrm{PB}$ (Tab. 2).

Tabela 1. Composição química dos ingredientes das dietas experimentais, com base na matéria seca $(\% \mathrm{MS})$

\begin{tabular}{lcccc}
\hline Itens & $\begin{array}{c}\text { Feno de parte aérea de } \\
\text { mandioca }\end{array}$ & Milho & $\begin{array}{c}\text { Farelo de } \\
\text { soja }\end{array}$ & $\begin{array}{c}\text { Casca de } \\
\text { mandioca }\end{array}$ \\
\hline Matéria seca (\%) & 91,28 & 90,16 & 91,97 & 90,64 \\
Matéria orgânica (\%) & 92,4 & 98,38 & 93,57 & 98,0 \\
Proteína bruta (\%) & 17,83 & 9,43 & 46,51 & 5,55 \\
Extrato etéreo (\%) & 4,77 & 2,22 & 2,34 & 0,67 \\
Fibra detergente neutro (\%) & 67,32 & 12,53 & 21,39 & 22,65 \\
Fibra detergente ácido (\%) & 56,62 & 2,13 & 6,27 & 14,36 \\
Hemicelulose & 10,70 & 10,40 & 15,12 & 4,65 \\
Lignina & 15,49 & 1,20 & 1,60 & 7,93 \\
\hline
\end{tabular}

Tabela 2. Composição percentual dos ingredientes das dietas em função dos níveis de inclusão de casca de mandioca

\begin{tabular}{lcccc}
\hline & \multicolumn{3}{c}{ Níveis de casca de mandioca } \\
\cline { 2 - 4 } Itens & $0 \%$ & $10 \%$ & $20 \%$ & $30 \%$ \\
\hline Feno de parte aérea de mandioca & 48,34 & 48,34 & 48,34 & 48,34 \\
\hline Milho & 47,79 & 36,49 & 25,10 & 14,0 \\
Farelo de soja & 3,14 & 4,44 & 5,77 & 6,83 \\
Casca da mandioca & 0,00 & 10,0 & 20,0 & 30,0 \\
Sal mineral & 0,48 & 0,48 & 0,48 & 0,48 \\
Fosfato bicálcio & 0,18 & 0,24 & 0,30 & 0,34 \\
\hline Composição química & & & & 90,74 \\
\hline MS (\%) & 90,30 & 90,84 & 91,84 & 94,28 \\
MO (\%) & 94,92 & 94,47 & 94,51 & 15,75 \\
PB (\%) & 15,49 & 15,29 & 15,44 & 2,71 \\
EE (\%) & 3,17 & 3,02 & 2,81 & 47,62 \\
FDN (\%) & 42,94 & 43,11 & 43,46 & 28,11 \\
FDA (\%) & 24,79 & 24,63 & 25,42 & 40,36 \\
FDN corrigido cinzas e proteína (\%) & 38,19 & 39,38 & 41,17 & 10,97 \\
Lignina (\%) & 7,94 & 9,34 & 9,62 & 35,51 \\
Carboidratos não fibrosos (\%) & 38,68 & 36,96 & 34,78 & 75,86 \\
Carboidratos totais (\%) & 76,87 & 76,35 & 75,95 & \\
\hline Nivis
\end{tabular}

Níveis de garantia (nutrientes/kg): cálcio-150g; enxofre-12g; fósforo-65g; magnésio-6.000mg; sódio-107g; cobre$100 \mathrm{mg}$; cobalto-175mg; ferro-1000mg; flúor máximo-650mg; iodo-175mg; manganês-1440mg; selênio-27mg e zinco- $6000 \mathrm{mg}$.

O experimento teve duração de 70 dias, sendo sete dias de adaptação às instalações e às dietas experimentais, e três períodos de 21 dias para avaliação e coleta de dados. Neste período, foram feitos os ajustes de consumo por meio da pesagem do alimento fornecido e das sobras, admitindo-se $10 \%$ da quantidade ofertada. As dietas foram oferecidas duas vezes ao dia, às oito 
horas e às 16 horas, na forma de mistura completa, com água à vontade. Após o período experimental, os animais foram submetidos a jejum de sólido por 16h, período que antecede o abate, para a obtenção do peso corporal final. Após o abate, foi determinado o peso, e a carcaça foi conduzida à câmara fria, onde permaneceu por $24 \mathrm{~h}$, a uma temperatura de $4^{\circ} \mathrm{C}$. Na meiacarcaça esquerda, entre a $12^{\mathrm{a}}$ e a $13^{\mathrm{a}}$ costela, foi retirado o músculo Longíssimus, cujas amostras foram mantidas congeladas $\left(4^{\circ} \mathrm{C}\right)$, até o início das análises, quando, então, estas foram descongeladas em temperatura ambiente, trituradas, homogeneizadas em microprocessador e analisadas.

As análises de umidade, cinzas e proteína foram realizadas conforme descrito por Silva e Queiroz (2002). Os lipídeos totais foram determinados seguindo metodologia de Bligh e Dyer (1959).
Para extração da matéria graxa dos ingredientes da ração e para a determinação do perfil em ácidos graxos, na etapa de extração lipídica por Bligh e Dyer (1959), foi corrigido o teor de umidade para $80 \%$.

A transesterificação dos triacilgliceróis foi realizada conforme o método (Animal..., 1978). Os ésteres metílicos foram analisados por meio de cromatógrafo gasoso (Thermo-Finnigan). As áreas de picos foram determinadas pelo método da normalização, utilizando-se um software Chrom Quest 4.1. Os valores percentuais dos ácidos graxos foram obtidos após a normalização das áreas. Os picos foram identificados por comparação dos tempos de retenção de padrões de ésteres metílicos de ácidos graxos Sigma (EUA) e após verificação do comprimento equivalente de cadeia.

Tabela 3. Composição dos ácidos graxos nos níveis de inclusão de casca de mandioca das dietas experimentais $(\%)$

\begin{tabular}{|c|c|c|c|c|}
\hline \multirow[t]{2}{*}{ Ácidos graxos } & \multicolumn{4}{|c|}{ Tratamentos } \\
\hline & $0 \%$ & $10 \%$ & $20 \%$ & $30 \%$ \\
\hline 16:0 palmítico & 15,70 & 15,85 & 21,91 & 22,26 \\
\hline 17:0 margárico & 0,29 & 0,28 & 0,26 & 0,25 \\
\hline 17:01 heptadecanoico & 0,05 & 0,08 & 0,13 & 0,14 \\
\hline 18:00 esteárico & 6,71 & 6,32 & 6,30 & 5,16 \\
\hline 18:1n-9c oleico & 43,45 & 43,30 & 43,26 & 34,15 \\
\hline 18:2n-6 linoleico & 32,21 & 34,54 & 34,97 & 35,61 \\
\hline 18:3n-6 y-linolênico & 0,73 & 0,66 & 0,26 & n.d. \\
\hline 20:00 araquídico & 0,87 & 0,86 & 0,86 & 0,68 \\
\hline 18:3n-3 $\alpha$ linolênico & 0,54 & 1,60 & 1,73 & 2,87 \\
\hline 21:00 heneicosanoico & 0,20 & 0,21 & 0,22 & 0,27 \\
\hline 20:3n-6 y-linolênico & n.d. & 0,99 & 1,51 & 1,70 \\
\hline 22:00 behênico & n.d. & 0,06 & 0,16 & 0,39 \\
\hline $20: 3 n-3$ eicosatrienoico & 0,90 & 0,99 & 1,05 & 2,09 \\
\hline 24:00 tetracosananoico & 0,23 & 0,23 & 0,25 & 0,38 \\
\hline \multicolumn{5}{|c|}{ Somatórios de ácidos graxos } \\
\hline AGS & 24,05 & 23,80 & 29,97 & 29,39 \\
\hline AGM & 43,50 & 43,38 & 43,39 & 34,29 \\
\hline AGPI & 34,38 & 38,77 & 39,52 & 42,27 \\
\hline$n-3$ & 1,44 & 2,58 & 2,78 & 4,96 \\
\hline$n-6$ & 32,94 & 36,19 & 36,74 & 37,31 \\
\hline n6/n3 & 22,89 & 14,01 & 13,21 & 7,53 \\
\hline AGPI/AGS & 1,43 & 1,63 & 1,32 & 1,44 \\
\hline
\end{tabular}

Não identificado (n.d.). AGS (ácidos graxos saturados), AGM (ácidos graxos monoinsaturados), AGPI (ácidos graxos poli-insaturados), n-3 (ômega 3), n-6 (ômega 6).

As análises estatísticas dos dados foram realizadas utilizando-se o programa SAEG Sistema de Análises Estatísticas e Genéticas, por meio da análise de variância e regressão, adotando-se o nível de 5\% de significância. 


\section{RESULTADOS E DISCUSSÃO}

Não foram observados efeitos significativos $(\mathrm{P}>0,05)$ dos níveis de inclusão da casca de mandioca $(\mathrm{CM})$ para as variáveis umidade, cinza e proteína, porém houve efeito para os teores de lipídeos, como se observa na Tab. 4.

O valor médio para o teor de cinza observado neste trabalho foi de $1,03 \%$, valor próximo ao de Prado (2004), o qual cita que, para tecidos cárneos, esse valor encontra-se ao redor de $1 \%$.
De acordo com Madruga et al. (2006), que trabalharam com ovinos Santa Inês e mestiços, não houve diferença significativa para as análises de cinzas $(0,98$ e $1,2 \%)$. Os teores de cinzas contidos na carne possuem funções biológicas importantes, pois são constituintes de hormônios, enzimas, entre outros (Pardi, 2001). A carne ovina contém aproximadamente 19\% de proteína segundo Prata (1999). Maior teor de proteína foi observado neste trabalho, com média de $25,6 \%$.

Tabela 4. Composição centesimal do músculo Longíssimus Dorsi de cordeiros alimentados com dietas contendo níveis de inclusão de casca de mandioca

\begin{tabular}{|c|c|c|c|c|c|c|c|c|c|}
\hline \multirow[b]{2}{*}{ Itens } & \multicolumn{4}{|c|}{ Dieta } & \multirow[b]{2}{*}{ EP } & \multicolumn{4}{|c|}{ Valor: P } \\
\hline & $0 \%$ & $10 \%$ & $20 \%$ & $30 \%$ & & Média & $\mathrm{L}$ & Q & C \\
\hline Umidade & 69,51 & 69,71 & 70,76 & 71,23 & 0,391 & 70,3 & 0,089 & 0,864 & 0,689 \\
\hline Cinzas & 1,04 & 0,99 & 1,10 & 0,99 & 0,022 & 1,03 & 0,900 & 0,561 & 0,080 \\
\hline Proteína & 24,92 & 25,97 & 25,19 & 26,32 & 0,451 & 25,6 & 0,401 & 0,965 & 0,360 \\
\hline Lipídeo & 8,35 & 6,13 & 6,33 & 4,62 & 0,369 & 6,35 & ${ }^{1} 0,002$ & 0,401 & 0,401 \\
\hline
\end{tabular}

${ }^{1} \hat{Y}=-0,1098 \mathrm{x}+8,0057\left(\mathrm{r}^{2}=0,8581\right) ; \mathrm{EP}$ (erro-padrão); L (linear), Q (quadrático); C (cúbico).

Efeito linear decrescente foi observado para os teores de lipídeos (Tab. 4). Tal resultado pode ser explicado, provavelmente, pela menor concentração energética da $\mathrm{CM}$ em relação ao milho, mesmo não sendo encontrado no consumo de NDT, mas foi suficiente para que os teores de lipídeos diminuíssem no músculo Longíssimus. Segundo Pinheiro et al. (2012), o teor de extrato etéreo na carne ovina pode ser em razão da alimentação, do tipo de músculo, do peso de abate e, também, do estágio fisiológico em que o animal se encontra. Os teores de umidade, lipídeos e proteína foram semelhantes aos encontrados por Madruga et al. (2008), com composição química da carne ovina apresentando valores médios de $73 \%$ de umidade, $23 \%$ de proteína e $4 \%$ de gordura. Os dados demonstram que não houve efeito significativo $(\mathrm{P}>0,05)$ com a inclusão da $\mathrm{CM}$ para os ácidos graxos saturados: C16:0, C17:0, C20:0 e C21:0; monoinsaturados: C14:1; e poliinsaturados: C18:2n-6, C18:3n-3 e C20:3n-3 do músculo Longíssimus (Tab. 5).

Foi observado efeito quadrático para o ácido mirístico C14:0, com valor mínimo de 1,93 para o nível próximo de $11,61 \%$ de CM (Tab. 5). Segundo French et al. (2003), o C14:0 tem efeito hipercolesterolêmico. No entanto, de acordo com os valores encontrados, o efeito do ácido mirístico no músculo Longíssimus não implica altos níveis de colesterol. Além disso, a maioria dos ácidos graxos saturados pode apresentar efeito da idade de abate. A carne de ovinos é considerada rica em ácidos graxos saturados, pois os microrganismos do rúmen hidrogenam extensivamente os ácidos graxos da dieta. Os ácidos graxos mais encontrados nesta espécie são o mirístico $(2,04 \%-3,65 \%)$, o palmítico $(20,88 \%$ $24,22 \%)$ e o esteárico (11,89\%-15,09\%) (Perez et al., 2002).

Houve efeito linear decrescente para o ácido C15:0, devido à inclusão da $\mathrm{CM}$; os níveis de fibra aumentaram, o que pode ter influenciado a diminuição da produção do ácido propiônico, que, por sua vez, contribui para a formação do ácido C15:0. Além disso, Fernandes et al. (2009) citam que os ácidos graxos de cadeia ímpar em ruminantes são formados pela síntese de novo, pelo ácido propiônico, produzido no processo de fermentação ruminal. A síntese de novo dos ácidos graxos ocorre por meio de uma série de reações enzimáticas iniciadas pela presença do acetil - CoA no citossol.

$\mathrm{Na}$ concentração dos ácidos graxos saturados, o palmítico (C16:0), considerado hipercolesterolêmico (Dietschy, 1998), não foi influenciado $(\mathrm{P}>0,05)$ pelos níveis de $\mathrm{CM}$ na ração, apesar de o ácido palmítico estar principalmente relacionado à dieta dos animais. Madruga et al. (2005) encontraram média de $23,53 \%$ para o ácido palmítico na carne de cordeiros da raça Santa Inês, sendo este valor próximo ao encontrado neste trabalho. 
Tabela 5. Quantidade de ácidos graxos (percentual) presentes nas amostras do músculo Longíssimus Dorsi de cordeiros alimentados com diferentes níveis de inclusão de casca de mandioca

\begin{tabular}{|c|c|c|c|c|c|c|c|c|}
\hline \multicolumn{9}{|c|}{ Dieta } \\
\hline Ácidos graxos & $0 \%$ & $10 \%$ & $20 \%$ & $30 \%$ & EP & $\mathrm{L}$ & Q & $\mathrm{C}$ \\
\hline \multicolumn{9}{|l|}{ Saturados } \\
\hline 14:0 mirístico & 2,488 & 2,355 & 2,490 & 2,919 & 0,068 & 0,001 & ${ }^{1} 0,001$ & 0,001 \\
\hline 15:0 pentadecanoico & 0,925 & 0,701 & 0,641 & 0,582 & 0,028 & ${ }^{2} 0,002$ & 0,001 & 0,737 \\
\hline 16:0 palmítico & 23,695 & 22,017 & 25,165 & 24,431 & 0,414 & 0,159 & 0,573 & 0,026 \\
\hline 17:0 margárico & 1,855 & 2,143 & 1,695 & 2,243 & 0,060 & 0,197 & 0,292 & 0,003 \\
\hline 18:0 esteárico & 13,796 & 18,087 & 15,196 & 15,857 & 0,384 & 0,346 & ${ }^{3} 0,025$ & 0,004 \\
\hline 20:0 araquídico & 0,106 & 0,147 & 0,092 & 0,159 & 0,006 & 0,056 & 0,284 & 0,001 \\
\hline 21:0 heneicosanoico & 0,015 & 0,017 & 0,014 & 0,018 & 0,003 & 0,307 & 0,459 & 0,018 \\
\hline 22:0 behênico & 0,021 & 0,026 & 0,145 & 0,034 & 0,004 & 0,001 & ${ }^{4} 0,001$ & 0,001 \\
\hline \multicolumn{9}{|l|}{ Monoinsaturados } \\
\hline 14:1 miristoleico & 0,325 & 0,309 & 0,300 & 0,309 & 0,018 & 0,740 & 0,731 & 0,950 \\
\hline 15:1 pentadecanoico & 0,393 & 0,454 & 3,022 & 1,048 & 0,086 & 0,001 & ${ }^{5} 0,001$ & 0,001 \\
\hline 16:1 palmitoleico & 1,896 & 1,259 & 1,855 & 1,293 & 0,054 & ${ }^{6} 0,019$ & 0,732 & 0,001 \\
\hline 17:1 Heptadecanoico & 2,008 & 1,581 & 1,674 & 1,773 & 0,062 & 0,280 & ${ }^{7} 0,043$ & 0,361 \\
\hline $18: 1 \mathrm{n}-9 \mathrm{c}$ oleico & 47,372 & 48,770 & 45,211 & 43,445 & 0,771 & ${ }^{8} 0,034$ & 0,314 & 0,336 \\
\hline 20:1 gadoleico & 0,057 & 0,077 & 0,048 & 0,222 & 0,007 & 0,001 & ${ }^{9} 0,001$ & 0,001 \\
\hline $22: 1$ n-9 erúcico & 0,093 & 0,379 & 0,130 & 1,755 & 0,006 & ${ }^{10} 0,001$ & 0,001 & 0,001 \\
\hline \multicolumn{9}{|l|}{ Poli-insaturados } \\
\hline 18:2n-6 linoleico & 1,445 & 1,467 & 1,550 & 1,609 & 0,052 & 0,226 & 0,864 & 0,859 \\
\hline 18:2 9c, 11t CLA & 0,692 & 0,518 & 0,492 & 0,361 & 0,018 & ${ }^{11} 0,001$ & 0,574 & 0,144 \\
\hline 18:2 10t, 12c CLA & 0,156 & 0,155 & 0,105 & 0,124 & 0,004 & ${ }^{12} 0,001$ & 0,248 & 0,004 \\
\hline 20:2 eicosadienoico & 0,006 & 0,008 & 0,007 & 0,001 & 0,003 & 0,001 & ${ }^{13} 0,001$ & 0,514 \\
\hline 18:3n-3 $\alpha$ linolênico & 0,400 & 0,369 & 0,426 & 0,316 & 0,017 & 0,214 & 0,253 & 0,106 \\
\hline $20: 3 n-3$ & & & & & 0,011 & 0,364 & 0,584 & 0,665 \\
\hline eicosatrienoico & 0,240 & 0,246 & 0,242 & 0,272 & & & & \\
\hline 18:3n-6 y-linolênico & 0,037 & 0,050 & 0,035 & 0,034 & 0,001 & 0,039 & ${ }^{14} 0,016$ & 0,001 \\
\hline 20:3n-6 y-linolênico & 0,032 & 0,036 & 0,038 & 0,044 & 0,001 & ${ }^{15} 0,001$ & 0,491 & 0,635 \\
\hline $20: 4 n-6$ & & & & & 0,003 & ${ }^{16} 0,001$ & 0,123 & 0,095 \\
\hline araquidônico & 0,078 & 0,090 & 0,086 & 0,122 & & & & \\
\hline $20: 5 n-3$ EPA & 0,031 & 0,026 & 0,067 & 0,069 & 0,005 & ${ }^{17} 0,008$ & 0,751 & 0,162 \\
\hline 22:6n-3 DPA & 0,109 & 0,132 & 0,125 & 0,154 & 0,006 & ${ }^{18} 0,007$ & 0,633 & 0,001 \\
\hline \multicolumn{9}{|c|}{$\begin{array}{l}{ }^{1} \hat{\mathrm{Y}}=0,0033 \mathrm{x}^{2}-0,0766 \mathrm{x}+2,3764\left(\mathrm{r}^{2}=0,7297\right) ;{ }^{2} \hat{\mathrm{Y}}=-0,0109 \mathrm{x}+0,8757\left(\mathrm{r}^{2}=0,8785\right) ;{ }^{3} \hat{\mathrm{Y}}=-0,0091 \mathrm{x}^{2}+0,3052 \mathrm{x}+ \\
14,332\left(\mathrm{r}^{2}=0,3998\right) ;{ }^{4} \hat{\mathrm{Y}}=-0,0003 \mathrm{x}^{2}+0,0102 \mathrm{x}+0,0041\left(\mathrm{r}^{2}=0,4389\right) ;{ }^{5} \hat{\mathrm{Y}}=-0,0051 \mathrm{x}^{2}+0,198 \mathrm{x}+0,0405\left({ }^{2}=0,4537\right) ; \\
\hat{\mathrm{Y}}=-0,0121 \mathrm{x}+1,7576\left(\mathrm{r}^{2}=0,2033\right) ;{ }^{7} \hat{\mathrm{Y}}=0,0013 \mathrm{x}^{2}-0,0456 \mathrm{x}+1,9826 \mathrm{r}^{2}=0,869 ;{ }^{8} \hat{\mathrm{Y}}=-0,1534 \mathrm{x}+48,5\left(\mathrm{r}^{2}=0,7109\right) ; \\
{ }^{9} \hat{\mathrm{Y}}=0,0004 \mathrm{x}^{2}-0,0069 \mathrm{x}+0,0698\left(\mathrm{r}^{2}=0,8384\right) ;{ }^{10} \hat{\mathrm{Y}}=0,0474 \mathrm{x}-0,1218\left(\mathrm{r}^{2}=0,603\right) ;{ }^{11} \hat{\mathrm{Y}}=-0,0102 \mathrm{x}+0,6682\left(\mathrm{r}^{2}=\right. \\
0,9338) ;{ }^{12} \hat{\mathrm{Y}}=-0,0014 \mathrm{x}+0,1568\left(\mathrm{r}^{2}=0,5702\right) ;{ }^{13} \hat{\mathrm{Y}}=-0,00002 \mathrm{x}^{2}+0,0006 \mathrm{x}+0,0054\left(\mathrm{r}^{2}=0,9963\right) ;{ }^{14} \hat{\mathrm{Y}}=-3 \mathrm{E}-05 \mathrm{x}^{2}+ \\
0,0007 \mathrm{x}+0,0396\left(\mathrm{r}^{2}=0,4535\right) ;{ }^{15} \hat{\mathrm{Y}}=0,0004 \mathrm{x}+0,0318\left(\mathrm{r}^{2}=0,9618\right) ;{ }^{16} \hat{\mathrm{Y}}=0,0013 \mathrm{x}+0,0746\left(\mathrm{r}^{2}=0,7303\right) ; \\
0, \hat{\mathrm{Y}}=0,0016 \mathrm{x}+0,0249\left(\mathrm{r}^{2}=0,7741\right) ;{ }^{18} \hat{\mathrm{Y}}=0,0013 \mathrm{x}+0,1111\left(\mathrm{r}^{2}=0,7876\right) .\end{array}$} \\
\hline
\end{tabular}

Houve efeito quadrático para o ácido esteárico (C18:0), com valor máximo de 16,89 para o nível próximo de 16,76\% de CM. O C18:0 (Tab. 5), um dos que obtiveram maior concentração no músculo Longíssimos, é considerado neutro, não exercendo efeito de elevação do colesterol, de acordo com Scollan et al. (2006).
Foi observado efeito quadrático para o ácido behênico (C22:0), com valor máximo de 0,0904 para o nível próximo de $17 \%$ de casca de mandioca. Tal resultado pode ter relação com a variação do C22:0 na dieta, pois este é um ácido graxo saturado e não sofre alteração no rúmen. 
Para os ácidos graxos monoinsaturados, foi verificado efeito quadrático para o pentadecanoico (C15:1), com valor máximo de 1,96\% para o nível próximo de $19,41 \%$ de CM.

Observa-se efeito linear decrescente para o C16:1. Esse efeito pode ter ocorrido devido ao aumento da fração fibrosa com a inclusão da $\mathrm{CM}$, diminuindo a concentração desse ácido graxo insaturado por causa da bio-hidrogenação. Segundo Visentainer et al., (2003), alguns ácidos graxos são dessaturados no organismo, tendo como precursores os ácidos graxos palmítico e esteárico, que dão origem aos ácidos graxos palmitoleico (C16:1n-7) e oleico (C18:1n-9).

Outro ácido graxo que foi alterado $(\mathrm{P}<0,05)$ de forma quadrática foi o $\mathrm{C} 17: 1$, com valor mínimo de $1,58 \%$ para o nível de $17,53 \%$ de casca de mandioca (Tab. 5). Os ácidos graxos de cadeia ímpar, como o $\mathrm{C} 17: 1$, são sintetizados pelas bactérias com a utilização de propionato e estão presentes nos lipídeos microbianos (Mansbridge e Blake, 1997)

Observa-se comportamento linear decrescente para o ácido oleico (C18:1). Esse fator pode ter ocorrido devido ao aumento do FDN na dieta com a inclusão da casca de mandioca, favorecendo a bio-hidrogenação, e este ácido graxo foi o que teve maior concentração. Elevada concentração também foi relatada por Madruga et al. (2006), os quais observaram que dietas ricas em ácido oleico proporcionam redução nos teores de colesterol total plasmático, no percentual de LDL e na relação LDL/ HDL.

Efeito quadrático foi observado para C20:01, com valor mínimo de 0,040 para o nível com $8,62 \%$ de casca de mandioca (Tab. 5).

Nas concentrações de ácidos graxos poliinsaturados, o ácido linoleico conjugado (CLA) obteve comportamento linear decrescente $(\mathrm{P}<0,05)$ nos níveis de inclusão da CM. A casca de mandioca propiciou teor de fibra crescente nas dietas experimentais, sendo esta importante para a concentração de microrganismos celulolíticos, que são necessários no processo de bio-hidrogenação, portanto explica-se o efeito decrescente do CLA. O CLA na carne traz benefícios à saúde humana, como ação antiinflamatória e diminuição dos sintomas do diabetes (Pariza, 2002; Beluty et al., 2003), e a maioria das pesquisas tem focalizado dois isômeros: o trans- 10, cis-12 CLA e o cis-9, trans-11 CLA, sendo o último com maior predominância nos produtos de ruminantes.

Foi identificado efeito quadrático para o C20:2, com valor máximo de 0,0099 para o nível próximo de $15 \%$ de CM (Tab. 5). Verifica-se efeito quadrático para o C18:3-6n, com valor máximo de 0,0436 para o nível de $11,6 \%$ de casca de mandioca.

Foi observado efeito linear crescente para os C20:3n-6, C20:4n-6, EPA e DPA. O C20:3n-6 teve comportamento crescente, provavelmente pelo aumento deste na dieta e o escape da ação dos microrganismos. Não foram detectados nas dietas o araquidônico (C20:4n-6), o eicosapentaenoico (EPA) e o docosapentaenoico (DPA). O araquidônico é encontrado em produtos de origem animal, porém o ácido linoleico, que não é sintetizado pelos mamíferos, mas sim obtido das dietas, é o precursor para a biossíntese do ácido araquidônico, eicosapentaenoico-EPA e do docosapentaenoicoDPA (Wood e Fisher, 1990), e como o linoleico está presente na dieta experimental (Tab. 3), e este aumentou com a inclusão da casca de mandioca, logo se explica o efeito crescente do C20:4n-6, EPA e DPA.

Os valores médios dos somatórios de ácidos graxos podem ser verificados na Tab. 6 .

Foi identificado efeito linear crescente para as variáveis somatórias dos AGS, com maior concentração na dieta com $30 \%$ de CM. Em cordeiros, os ácidos graxos poli-insaturados da dieta são bio-hidrogenados no rúmen, resultando na absorção de ácidos graxos saturados pelo intestino, o que explica por que a carne ovina possui alta concentração de ácidos graxos saturados e baixa relação de ácidos graxos poliinsaturados:saturados AGPI:AGS (Cooper et al., 2004). Houve efeito linear decrescente com relação ao somatório do CLA (Tab. 6). Os níveis de CLA no músculo Longíssimus diminuíram, por conseguinte o somatório deste é menor. 
Tabela 6. Valores médios relativos aos somatórios de ácidos graxos na amostra do músculo Longíssimus Dorsi de cordeiros alimentados com níveis de inclusão de casca de mandioca

\begin{tabular}{|c|c|c|c|c|c|c|c|c|}
\hline & \multicolumn{4}{|c|}{ Tratamentos } & \multicolumn{4}{|c|}{ Valor: P } \\
\hline Ácidos graxos & $0 \%$ & $10 \%$ & $20 \%$ & $30 \%$ & EP & $\mathrm{L}$ & $\mathrm{Q}$ & $\mathrm{C}$ \\
\hline$\sum \mathrm{AGS}^{1}$ & 42,666 & 45,086 & 45,439 & 46,495 & 0,4981 & ${ }^{1} 0,013$ & 0,499 & 0,539 \\
\hline$\sum \mathrm{AGM}^{2}$ & 53,406 & 52,486 & 52,254 & 49,868 & 0,6746 & 0,083 & 0,591 & 0,640 \\
\hline$\sum \mathrm{AGPI}^{3}$ & 3,228 & 3,130 & 3,173 & 3,106 & 0,0704 & 0,612 & 0,914 & 0,695 \\
\hline$\sum \mathrm{CLA}^{4}$ & 0,861 & 0,702 & 0,598 & 0,486 & 0,0196 & ${ }^{2} 0,001$ & 0,550 & 0,722 \\
\hline$\sum n-6^{5}$ & 1,608 & 1,664 & 1,833 & 1,963 & 0,0529 & ${ }^{3} 0,015$ & 0,733 & 0,748 \\
\hline$\sum n-3^{6}$ & 0,665 & 0,641 & 0,735 & 0,657 & 0,0185 & 0,672 & 0,473 & 0,091 \\
\hline AGPI/AGS ${ }^{7}$ & 0,076 & 0,070 & 0,070 & 0,067 & 0,0018 & 0,092 & 0,914 & 0,914 \\
\hline$n-6 / n-3^{8}$ & 2,398 & 2,633 & 2,523 & 3,107 & 0,0905 & ${ }^{4} 0,018$ & 0,691 & 0,578 \\
\hline
\end{tabular}

${ }^{1}$ Somatório de ácidos graxos saturados; ${ }^{2}$ somatório de ácidos graxos monoinsaturados; ${ }^{3}$ somatório de ácidos graxos poli-insaturados; ${ }^{4}$ somatório do ácido linoleico conjugado; ${ }^{5}$ somatório do ômega-6; ${ }^{6}$ somatório do ômega-3; ${ }^{7}$ relação entre os ácidos graxos poli-insaturados e saturados; ${ }^{8}$ relação entre os ácidos graxos da família ômega-6 e ômega-3. ${ }^{1} \hat{\mathrm{Y}}=0,1184 \mathrm{x}+43,146\left(\mathrm{r}^{2}=0,8919\right) ;{ }^{2} \hat{\mathrm{Y}}=-0,0123 \mathrm{x}+0,8458\left(\mathrm{r}^{2}=0,99\right) ;{ }^{3} \hat{\mathrm{Y}}=0,0124 \mathrm{x}+1,5815\left(\mathrm{r}^{2}=0,968\right)$; ${ }^{4} \hat{Y}=0,0202 x+2,363\left(r^{2}=0,7063\right) ; L$ (linear); Q (quadrática); C (cúbica).

A quantidade de n-6 também aumentou, fato que pode ser explicado pelo aumento dos ácidos graxos desta família no músculo Longíssimus. A razão n-6/n-3 aumentou linearmente com a adição da CM. Recomenda-se manter uma razão ótima entre n-6:n-3 em níveis inferiores a 4\% (Nutritional... 1994) para diminuição dos riscos de doenças. Existe competição entre os ácidos graxos das famílias n-6 e n-3 pelas enzimas envolvidas nas reações de dessaturação e alongamento da cadeia, assim é importante existir equilíbrio entre n- 6 e n-3, pois um excesso de $n-6$ pode impedir, por causa da competição, a transformação do ácido graxo da família n-3 em seus derivados de cadeia longa, segundo Martin et al. (2006).

\section{CONCLUSÃO}

A inclusão da casca de mandioca influenciou no teor lipídico do músculo Longíssimus de cordeiros mestiços Santa Inês, bem como na composição de alguns ácidos graxos, porém a casca de mandioca pode ser utilizada na dieta desses animais sem comprometer a qualidade da carne.

\section{REFERÊNCIAS}

ANIMAL and vegetable fats and oils preparation of methyl esters of fatty acids. Geneve: ISO, 1978. p.1-6. (ISO 5509).

ARAÚJO, FILHO. J.T.; COSTA, R.G.; FRAGA, A.B. et al. Desempenho e composição da carcaça de cordeiros deslanados terminados em confinamento com diferentes dietas. Rev. Bras. Zootec., v.39, p.363-371, 2010.
BELURY, M.A.; MAHON, A.; BANNI, S. The conjugated linoleic acid (CLA) isomer, t10c12CLA, is inversely associated with changes in body weight and serum leptin in subjects with type 2 diabetes mellitus. J. Nutr., v.133, p.257S260S, 2003.

BLIGH, E.G.; DYER, W.J. A rapid method of total lipid extraction and purification. Can. J. Biochem. Physiol., v.37, p.911-917, 1959.

CASTRO FILHO, M.A.; BARBOSA, M.A.A.F., OLIVEIRA, R.L. et al. Valor nutritivo da palha de milho verde para bovinos. Rev. Bras. Saúde Prod. Anim., v.8, p.112-121, 2007.

COOPER, S.L.; SINCLAIR, L.A.; WILKINSON, R.G. et al. Manipulation of the n3 polyunsaturated fatty acid content of muscle and adipose tissue in lambs. J. Anim. Sci., v.82, p.1461-1470, 2004.

DIETSCHY, J.M. Dietary fatty acids and the regulation of plasma low density lipoprotein cholesterol. J. Nutr., v.128, p.444-448, 1998.

FERNANDES, A.R.M.; SAMPAIO, A.A.M.; HENRRIQUE, W. et al. Composição química e perfil de ácidos graxos da carne de bovinos de diferentes condições sexuais recebendo silagem de milho e concentrado ou cana de açúcar e concentrado contendo grão de girassol. Rev. Bras. Zootec., v.38, p.705-712, 2009.

FRENCH, P.; O'RIORDAN, E.G.; MONAHAN, F.J. et al. Fatty acid composition of intramuscular triacylglycerols of steers fed autumn grass and concentrates. Livest. Prod. Sci., v.81, p.307-317, 2003. 
HOLZER, Z.; AHARONI, Y., LUBIMOV, V. et al. The feasibility of replacement of grain by tapioca en diets for growing-fattening cattle. Anim. Feed Sci. Technol., v.64, p.133-142, 1997.

MADRUGA, M.S.; ARAÚJO, W.O.; SOUSA, W.H. et al. Efeito do genótipo e do sexo sobre a composição química e perfil dos ácidos graxos da carne de cordeiros. Rev. Bras. Zootec., v.35, Supl., p.1838-1844, 2006.

MADRUGA, M.S.; SOUSA, W.H.; ROSALES, M.D. et al. Qualidade da carne de cordeiros Santa Inês terminados com diferentes dietas. Rev. Bras. Zootec., v.34, p.309-315, 2005.

MADRUGA, M.S.; VIEIRA, T.R.L.; CUNHA, M.G.G. et al. Efeito de dietas com níveis crescentes de caroço de algodão integral sobre a composição química e o perfil de ácidos graxos da carne de cordeiros Santa Inês. Rev. Bras. Zootec., v.37, p.1496-1502, 2008.

MANSBRIDGE, R.J.; BLAKE, J.S. Nutritional factors affecting the fatty acid composition of bovine milk. Br. J. Nutr., v.78, Suppl.1, p.37-47, 1997.

MARTIN, C.A.; ALMEIDA, V.V.; RUIZ. M.R. et al. Ácidos graxos poliinsaturados ômega-3 e ômega-6: importância e ocorrência em alimentos. Rev. Nutr., v.19, p.761-770, 2006.

McAFEE, A.J.; McSORLEY, E.M.; CUSKELLY, G.J. et al. Red meat consumption: an overview of the risks and benefits. Meat Sci., v.84, p.1-13, 2010.

NUNES IRMÃO J.; FIGUEIREDO, M.P.; PEREIRA, L.G.R. et al. Composição química do feno da parte aérea da mandioca em diferentes idades de corte. Rev. Bras. Saúde Prod. Anim., v.9, p.158-169, 2008.

NUTRITIONAL aspects of cardiovascular disease: report of the cardiovascular review group. London: HMSO, 1994. 202p. (Report on Health and Social Subjects; 46).
PARDI, M.C. Ciência, higiene e tecnologia da carne. 2.ed. Goiânia: UFG, 2001. 586p.

PARIZA, M.W. Conjugated linoleic acid may be useful in treating diabetes by controlling body fat and weight gain. Diabetes Technol. Ther., v.4, p.335-338, 2002.

PEREZ, J.R.O.; BRESSAN, M.C.; BRAGAGNOLO, N. et al. Efeito do peso de abate de cordeiros Santa Inês e Bergamacia sobre o perfil de ácidos graxos, colesterol e propriedades químicas. Ciênc. Tecnol. Aliment., v.22, p.11-18, 2002.

PINHEIRO, R.S.B; JORGE, A.M; SOUZA, H.B.A. et al. Aceitação sensorial e composição centesimal da carne de ovelhas abatidas em diferentes estágios fisiológicos. Rev. Bras. Saúde Prod. Anim., v.64, p.1053-1059, 2012.

PRADO, I.N. Conceitos sobre a produção com qualidade de carne e leite. Maringá: UEM, 2004. $301 \mathrm{p}$.

PRATA, L.F. Higiene e inspeção de carnes, pescado e derivados. Jaboticabal: FUNEP, 1999. $217 \mathrm{p}$.

SCOLLAN, N.; HOCQETTE, J.F.; NUERNBERG, K. et al. Innovations in beef production systems that enhance the nutritional and health value of beef lipids and their relationship with meat quality. Meat Sci., v.74, p.17-33, 2006.

SILVA, D.J.; QUEIROZ A.C. Análise de alimentos (métodos químicos e biológicos). Viçosa: UFV, 2002. 235p.

VISENTAINER, J.V.; FRANCO, M.R.B.; VISENTAINER, J.E.L. et al. Essencialidade dos ácidos graxos de cadeia longa no homem: uma análise crítica. Rev. Nac. Carne, v.27, p.84-88, 2003.

WOOD, J.D.; FISHER, A.V. Reducing fat in meat animals. London: Elsevier Applied Science, 1990. 469p. 